\title{
Synthesis, size-dependent optoelectronic and charge transport properties of thieno(bis)imide end-substituted molecular semiconductors
}

\author{
Margherita Durso ${ }^{a}$, Cristian Bettini ${ }^{\mathrm{b}}$, Alberto Zanelli ${ }^{\mathrm{a}}$, Massimo Gazzano ${ }^{\mathrm{a}}$, M. Grazia Lobello ${ }^{\mathrm{c}}$, \\ Filippo De Angelis ${ }^{\mathrm{c}}$, Viviana Biondo ${ }^{\mathrm{d}}$, Denis Gentili ${ }^{\mathrm{e}}$, Raffaella Capelli ${ }^{\mathrm{e}, *}$, \\ Massimiliano Cavallini ${ }^{\mathrm{e}}$, Stefano Toffanin ${ }^{\mathrm{e}}$, Michele Muccini ${ }^{\mathrm{d}, \mathrm{e}, *}$, Manuela Melucci $^{\mathrm{a}, *}$ \\ ${ }^{a}$ Consiglio Nazionale delle Ricerche, Istituto per la Sintesi Organica e la Fotoreattività, (CNR-ISOF), via P. Gobetti 101, 40129 Bologna, Italy \\ ${ }^{\mathrm{b}}$ Laboratory MIST E-R, via P. Gobetti 101, 40129 Bologna, Italy \\ ' Consiglio Nazionale delle Ricerche, Istituto di Scienze e Tecnologie Molecolari (CNR-ISTM), via Elce di Sotto 8, I-6123 Perugia, Italy \\ ${ }^{\mathrm{d}}$ E.T.C. s.r.l., via P. Gobetti 101, 40129 Bologna, Italy \\ ' Consiglio Nazionale delle Ricerche, Istituto per lo studio dei Materiali Nanostrutturati (ISMN), via P. Gobetti 101, 40129 Bologna, Italy
}

\section{A R T I C L E I N F O}

\section{Article history:}

Received 15 April 2013

Received in revised form 1 July 2013

Accepted 15 July 2013

Available online 30 July 2013

\section{Keywords:}

Molecular semiconductors

Structure-property relationships

Ambipolar charge transport

Field effect transistors

Oligothiophenes

\begin{abstract}
A B S T R A C T
The synthesis of two new thieno(bis)imide (TBI, N) end functionalized oligothiophene semiconductors is reported. In particular, trimer (NT3N) and pentamer (NT5N) have been synthesized and characterized. Two different synthetic approaches for their preparation were tested and compared namely conventional Stille cross coupling and direct arylation reaction via $\mathrm{C}-\mathrm{H}$ activation. Theoretical calculations, optical and electrochemical characterization allowed us to assess the role of the $\pi$-conjugation extent, i.e., of the oligomer size on the optoelectronic properties of these materials. In both TBI ended compounds, due to the strong localization of the LUMO orbital on the TBI unit, the LUMO energy is almost insensitive to the oligomer size, this being crucial for the fine-tailoring of the energy and the distribution of the frontier orbitals. Surprisingly, despite its short size and contrarily to comparable TBI-free analogues, NT3N shows electron charge transport with mobility up to $\mu_{\mathrm{N}}=10^{-4} \mathrm{~cm}^{2} \mathrm{~V}^{-1} \mathrm{~s}^{-1}$, while increasing the oligomer size to NT5N promotes ambipolar behavior and electroluminescence properties with mobility up to $\mu_{\mathrm{N}}=0.14 \mathrm{~cm}^{2} \mathrm{~V}^{-1} \mathrm{~s}^{-1}$ and to $\mu_{\mathrm{P}}=10^{-5} \mathrm{~cm}^{2} \mathrm{~V}^{-1} \mathrm{~s}^{-1}$.
\end{abstract}

(c) 2013 Elsevier B.V. All rights reserved.

\section{Introduction}

Molecular organic semiconductors are currently matter of great interest for applications as active layers in charge transport based organic devices with the perspective of

\footnotetext{
* Corresponding authors. Addresses: CNR-ISMN via P. Gobetti 101, 40129 Bologna, Italy. Tel.: +39 0516398515; fax +39 0516398540 (R. Capelli), E.T.C. srl, via P. Gobetti 101, 40129 Bologna, Italy. Tel.: +39 0516398521; fax +39 0516398540 (M. Muccini), CNR-ISOF via P. Gobetti 101, 40129 Bologna, Italy. Tel.: +39 0516398271; fax +39 0516398349 (M. Melucci).

E-mail addresses: r.capelli@bo.ismn.cnr.it (R. Capelli), m.muccini@ bo.ismn.cnr.it (M. Muccini), manuela.melucci@isof.cnr.it (M. Melucci).
}

flexible electronics [1]. While exhaustive performance in devices and structure-properties correlations have been established for p-type semiconductors, n-type and ambipolar materials have been developed to a much lesser extent. In particular, ambipolar organic semiconductors (with both electron and hole charge transport capability) are key components for realizing complementary metal-oxide semiconductor (CMOS) digital integrated circuits [2] and organic light-emitting transistor (OLETs) devices [3]. Arylene(bis)imide frameworks are widely exploited building blocks to promote electron [4] and ambipolar charge transports [5]. Recently, we introduced the thieno(bis)imide (TBI, $\mathrm{N}$, Fig. 1 blue square) end functionalization route as a 


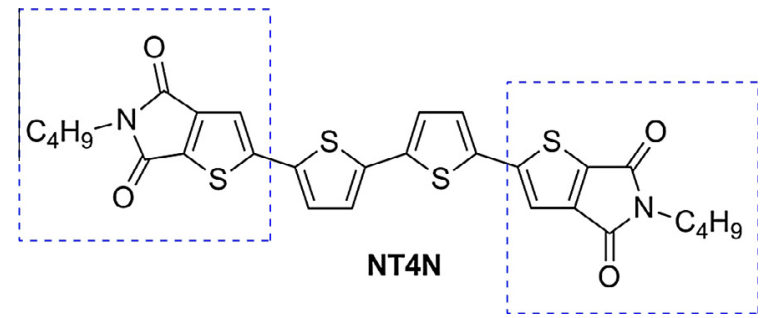

Fig. 1. Molecular structure of NT4N used here as reference compound (TBI building blocks highlighted in the blue squares). (For interpretation of the references to color in this figure legend, the reader is referred to the web version of this article.)

strategy to promote ambipolarity in thiophene based materials [6]. Indeed, TBI based quaterthiophenes of different molecular structures displayed ambipolar charge transport with major n-type behavior combined in most cases to electroluminescence, making these materials potential candidates to realize field effect transistors and single layer ambipolar light emitting transistor devices (OLETs) [3,6a$c, 7]$. It should be noted that linear oligothiophenes are generally unipolar p-type semiconductors, and so far only few cases of n-type and ambipolar systems have been reported $[1 \mathrm{a}, 8]$.

Among them quinoidal oligothiophene derivatives such as dicyanomethylene end-substituted systems, [9] have been largely investigated as potential candidates for the development of air stable n-type OFETs. Interestingly, switch from n-type to ambipolar behavior was demonstrated for a quinoidal quaterthiophene by changing the solvent used for the spin-coating processing [9c]. However, despite high n-type mobilities were measured for some of these compounds, electroluminescence have never been observed for such compounds, making our TBI materials a unique case of studies for the establishment of new design roles toward multifunctional semiconductors. Therefore, starting from our initial work on NT4N (Fig. 1) [6c] we decided to explore the full potential of our TBI based materials for applications in charge transport based devices. In particular, we recently studied the effect of the replacement of the bithiophene core of NT4N with cores featuring different electronic properties [6b] as well as the effect of the molecular asymmetry [6c] on the functional properties of the resulting tetrameric materials.

Based on this background, here we focus on the oligomer length i.e. different $\pi$-conjugation extent, as a pivotal tool to control the optoelectronic and electrical properties of TBI materials.

It should be noted that odd-membered oligothiophenes T5 and T7 based systems, have shown peculiar optical [10] self-organizing properties [11], and electrical properties with respect to even membered materials that have been most intensively studied over the past few years $[8,12,13]$. Accordingly, two new TBI odd-membered oligomers, trimer NT3N and pentamer NT5N were selected as model compounds and investigated [6c].

The optoelectronic properties and electrical behavior of the newly synthesized materials have been carefully investigated and compared to those of the recently reported NT4N [6a] tetramer and to those of conventional oligothi- ophenes having the same number of thiophene units (T3, $\mathrm{T} 4$ and $\mathrm{T} 5$ respectively). Two different synthetic approaches to these new compounds were tested and compared, i.e., conventional Stille cross coupling and direct arylation under Fagnou conditions [14]. This method has the key advantage of avoiding the use of organometallic species whose by-products remotion requires tedious purification steps [15]. Finally, n-type and ambipolar semiconducting behavior in OFET is observed for NT3N and NT5N, respectively, highlighting the general suitability of TBI-based materials as candidates for charge transport based devices.

\section{Experimental details}

\subsection{Synthesis}

\subsubsection{Synthesis of 2,2'-(thiophene-2,5-diyl)bis(5-butyl-5H- thieno(3,2-c)pyrrole-4,6-dione), NT3N, 3}

Stille coupling: tris(dibenzylideneacetone)dipalladiumchloroform adduct $(0.044 \mathrm{mmol})$ and triphenylarsine $(0.35 \mathrm{mmol})$ were dissolved in $20 \mathrm{ml}$ of dry toluene under $\mathrm{N}_{2}$ atmosphere and the solution was refluxed until the color turned to dark brown. Compound 2 [6c] (0.88 mmol) in $6 \mathrm{ml}$ of dry toluene was added and then the distannyl derivative $(0.40 \mathrm{mmol})$ in $2 \mathrm{ml}$ of dry toluene was added dropwise. The solution was refluxed for $24 \mathrm{~h}$ and then stirred at room temperature overnight. The solvent was removed under reduced pressure and the crude product purified by flash chromatography on silica gel followed by crystallization from toluene to give $130 \mathrm{mg}$ of NT3N as an orange powder (65\% yield).

Direct arylation: $\mathrm{K}_{2} \mathrm{CO}_{3}(0.21 \mathrm{mmol}, 1.5$ eq. $), \mathrm{Pd}(\mathrm{OAc})_{2}$ (0.008 mmol, $6 \mathrm{~mol} \%), \mathrm{PCy}_{3} \mathrm{HBF}_{4}(0.017 \mathrm{mmol}, 12 \mathrm{~mol} \%)$ and PivOH (0.042 mmol, $30 \mathrm{~mol} \%)$ were added in a twoneck round-bottom flask equipped with a magnetic stir bar and a refrigerator under $\mathrm{N}_{2}$ atmosphere. Compound $\mathbf{1}$ ( $0.35 \mathrm{mmol}, 2.5$ eq.) was added dissolved into dry toluene (2.5 ml). 2,5-Dibromothiophene ( $0.14 \mathrm{mmol}, 1$ eq.) was added and the reaction mixture was stirred at reflux temperature for $24 \mathrm{~h}$. The reaction mixture was then cooled to $\mathrm{rt}$, diluted with $\mathrm{H}_{2} \mathrm{O}$, and the product was extracted with $\mathrm{CH}_{2} \mathrm{Cl}_{2}$ (3 times). The combined organic layer was dried over $\mathrm{Na}_{2} \mathrm{SO}_{4}$ and evaporated under reduced pressure. The crude product was purified by flash chromatography on silica gel to give $21 \mathrm{mg}$ of NT3N (30\% yield).

NT3N characterization: M.p. $210^{\circ} \mathrm{C}$. MS (70 eV, EI): $\mathrm{m} / \mathrm{z}$ $498\left(\mathrm{M}^{+}\right) .{ }^{1} \mathrm{H}$ NMR $\left(400 \mathrm{MHz}, \mathrm{CDCl}_{3}, \mathrm{TMS} / \mathrm{ppm}\right): \delta 7.36(\mathrm{~s}$, $2 \mathrm{H}), 7.29(\mathrm{~s}, 2 \mathrm{H}), 3.62(\mathrm{t}, 4 \mathrm{H}), 1.63(\mathrm{~m}, 4 \mathrm{H}), 1.37(\mathrm{~m}, 4 \mathrm{H})$, $0.95(\mathrm{t}, 6 \mathrm{H}) ;{ }^{13} \mathrm{C} \mathrm{NMR}\left(100 \mathrm{MHz}, \mathrm{CDCl}_{3}, \mathrm{TMS} / \mathrm{ppm}\right): \delta$ $163.7,162.6,148.5,145.2,138.3,136.5,126.9,117.3$, 38.4, 30.8, 20.0, 13.6; UV-Vis: $\lambda_{\text {abs }}=428 \mathrm{~nm}\left(\mathrm{CH}_{2} \mathrm{Cl}_{2}\right)$; PL $\left(\lambda_{\text {exc }}=428 \mathrm{~nm}, \mathrm{CH}_{2} \mathrm{Cl}_{2}\right): \lambda_{\mathrm{em}}=526 \mathrm{~nm}$. Anal. calcd for $\mathrm{C}_{24-}$ $\mathrm{H}_{22} \mathrm{~N}_{2} \mathrm{O}_{4} \mathrm{~S}_{3}$ : C, 57.81; H, 4.45. Found: C, 57.77; H, 4.39.

\subsubsection{Synthesis of $2,2^{\prime}-\left(\left(2,2^{\prime}: 5^{\prime}, 2^{\prime \prime}\right.\right.$-terthiophene $)-5,5^{\prime \prime}-$ diyl)bis(5-butyl-4H-thieno(2,3-c)pyrrole-4,6(5H)-dione), NT5N, 4}

Stille coupling: the synthetic procedure was the same for NT3N. The following amount of reagents were used: $\mathrm{Pd}_{2}(\mathrm{dba})_{3}(0.02 \mathrm{mmol})$, and $\mathrm{AsPh}_{3}(0.16 \mathrm{mmol})$, toluene $(18 \mathrm{ml})$. Dark red powder (165 mg, 63\% yield). 
Direct arylation: The synthetic procedure was the same for NT3N but by using compound $\mathbf{5}(0.35 \mathrm{mmol})$ as the arylating substrate. Purification: the crude dissolved in hot toluene was filtered through Celite and then crystallized from toluene ( $23 \mathrm{mg}, 25 \%$ yield).

NT5N characterization: M.p. $300{ }^{\circ} \mathrm{C}$. MS (70 eV, EI): $\mathrm{m} / \mathrm{z}$ $662\left(\mathrm{M}^{+}\right) .{ }^{1} \mathrm{H}$ NMR $\left(400 \mathrm{MHz}, \mathrm{CDCl}_{3}, \mathrm{TMS} / \mathrm{ppm}\right): \delta 7.32(\mathrm{~s}$, $2 \mathrm{H}), 7.25\left(\mathrm{~d},{ }^{3} J=4.0 \mathrm{~Hz}, 2 \mathrm{H}\right), 7.17(\mathrm{~s}, 2 \mathrm{H}), 7.15$ (d, $3 J=4.0 \mathrm{~Hz}, 2 \mathrm{H}), 3.62(\mathrm{t}, 4 \mathrm{H}), 1.63(\mathrm{~m}, 4 \mathrm{H}), 1.38(\mathrm{~m}, 4 \mathrm{H})$, $0.97 \quad(\mathrm{t}, \quad 6 \mathrm{H}) . \quad$ UV-Vis: $\lambda_{\text {abs }}=465 \mathrm{~nm} \quad\left(\mathrm{CH}_{2} \mathrm{Cl}_{2}\right) ; \quad \mathrm{PL}$ $\left(\lambda_{\text {exc }}=465 \mathrm{~nm}, \mathrm{CH}_{2} \mathrm{Cl}_{2}\right): \lambda_{\mathrm{em}}=599 \mathrm{~nm}$. Anal. calcd for $\mathrm{C}_{32-}$ $\mathrm{H}_{26} \mathrm{~N}_{2} \mathrm{O}_{4} \mathrm{~S}_{5}$ : C, 57.98; H, 3.95. Found: C, 57.92; H, 3.88.

2.1.3. Synthesis of 5-butyl-2-(thiophen-2-yl)-4H-thieno(2,3c)pyrrole-4,6(5H)-dione, 5

The synthetic procedure was the same for the other compounds. The following amounts of reagents were used: $\mathrm{K}_{2} \mathrm{CO}_{3} \quad(1.5 \mathrm{mmol}), \quad \mathrm{Pd}(\mathrm{OAc})_{2} \quad(0.06 \mathrm{mmol}), \quad \mathrm{PCy}_{3} \mathrm{HBF}_{4}$ (0.12 mmol), PivOH $(0.3 \mathrm{mmol})$, compound 1 (1 mmol), toluene $(3 \mathrm{ml}), 2$-Bromothiophene $(1.5 \mathrm{mmol})$. Refluxing time: $6 \mathrm{~h}$. Purification by flash chromatography on silica gel. Yellow powder (204 mg, 70\% yield).

\subsection{Electrochemistry}

HOMO and LUMO energy levels have been estimated through the redox potentials of $1 \mathrm{mmol} \mathrm{L}^{-1}$ solution of NT3N in $\mathrm{CH}_{3} \mathrm{CN}$ (Carlo Erba RS Gold for HPLC, stored over molecular sieves $3 \mathrm{~A}$ under Ar pressure) with $0.1 \mathrm{~mol} \mathrm{~L}^{-1}$ $\left(\mathrm{C}_{4} \mathrm{H}_{9}\right)_{4} \mathrm{NClO}_{4}$ (Fluka, puriss. crystallized from $\mathrm{CH}_{3} \mathrm{OH}$ and vacuum dried). After Ar bubbling, cyclic voltammetries (CVs) were performed at scan rates within 0.02 and $0.2 \mathrm{~V} \mathrm{~s}^{-1}$, in a home-made three compartment glass cell under Ar pressure, by using an AMEL electrochemical system model 5000. Working electrode was semi-spherical Pt (area $0.05 \mathrm{~cm}^{2}$ ), auxiliary electrode was a Pt wire, and reference electrode was aqueous $\mathrm{KCl}$ Saturated Calomel Electrode (SCE) separated from the working electrode compartment by a liquid bridge containing the same solvent and support electrolyte. Ferrocene/ferricinium redox potential in $\mathrm{CH}_{3} \mathrm{CN} 0.1 \mathrm{~mol} \mathrm{~L}^{-1}\left(\mathrm{C}_{4} \mathrm{H}_{9}\right)_{4} \mathrm{NClO}_{4}$ was $0.40 \mathrm{~V}$ vs. SCE. NT5N, that is not soluble in $\mathrm{CH}_{3} \mathrm{CN}$, has been studied in the same condition but in saturated solution of $\mathrm{CH}_{2-}$ $\mathrm{Cl}_{2}$ (Carlo Erba RPE, distilled over phosphoric anhydride and stored under Ar pressure) where the redox potential of ferrocene/ferricinium was $0.47 \mathrm{~V}$ vs. SCE.

\subsection{Computational details}

The geometry of NT3N and NT5N compounds was optimized in their ground state in vacuum using B3LYP [16] exchange-correlation functional and $6-31 \mathrm{~g}^{*}$ basis set [17], using Gaussian03 [18] (G03) program package. The single points are performed in $\mathrm{CH}_{3} \mathrm{CN}$ solution using B3LYP exchange-correlation functional and $6-31 \mathrm{~g}^{*}$ basis set, using the CPCM [19] non-equilibrium version as implemented in G03.

\subsection{Atomic force microscopy}

AFM was performed in intermitted contact mode, using a Bruker Multimode 8 AFM.

\subsection{Optical properties}

NT3N and NT5N optical characterization in solid state was performed depositing $100 \mathrm{~nm}$-thick thin-film onto quartz substrate. UV-Visible absorption spectra were recorded with a JASCO V-550 spectrophotometer. Photoluminescence was excited using a CW He-Cd laser at $325 \mathrm{~nm}$ with $40 \mathrm{~mW}$ power. No PL cut-off filter was used. PL emission was collected with a calibrated optical multichannel analyzer (PMA-11, Hamamatsu).

\subsection{Field-effect transistors fabrication}

The transistors were fabricated in bottom gate-top contact geometry. The ITO substrate cleaning procedure consists of two sonication cycles, first in acetone and then in 2-propanol, for $10 \mathrm{~min}$ each. The $450 \mathrm{~nm}$ thick dielectric layer of PMMA has been grown by spin-coating on top of the clean ITO substrate (relative electric permittivity $\varepsilon=3.6$ at $100 \mathrm{~Hz}$ ). The PMMA film was then thermally annealed in a glove box at $120^{\circ} \mathrm{C}$ (around $10^{\circ} \mathrm{C}$ above the glass transition temperature for PMMA) for $15 \mathrm{~h}$ under inert atmosphere. (CPMMA $=7.08 \mathrm{nF} / \mathrm{cm}^{2}$ ).

The $30 \mathrm{~nm}$ thick layers have been grown by vacuum sublimation in a home-made vacuum chamber. The substrate temperature during the film deposition has been kept at room temperature (rt). The drain-source electrodes were made of gold and were evaporated through a shadow mask on top of the organic thin film. The gold layer thickness is $50 \mathrm{~nm}$, while the channel length and the channel width are $70 \mu \mathrm{m}$ and $15 \mathrm{~mm}$, respectively. The mobility values in saturation are calculated from the locus curves using the standard equations:

$\mu=L /(W * C) A^{2}$

where $A$ is the angular coefficient of the line fitting the square root of the drain current vs. the applied voltage, $L$ is the channel length, $W$ the channel width and $C$ is the transistor dielectric capacitance.

\section{Result and discussion}

\subsection{Synthesis}

The bromo derivative 2 [6c] was selected as starting material for both NT3N and NT5N (Scheme 1). Optimal reaction conditions required the use of in situ prepared $\operatorname{Pd}\left(\mathrm{AsPh}_{3}\right)_{4}$ catalyst and the corresponding bis-stannyl thienyl compounds under refluxing toluene. The targeted oligomers 3 and 4 were isolated in 65\% and 63\% yields, respectively, upon chromatographic purification and subsequent crystallization (toluene).

The direct $\mathrm{C}-\mathrm{H}$ arylation was also tested due to the undoubted advances in terms of step and atom economy [15]. In particular, it would allow the avoiding of bromination of the compound 1 which generally requires long reaction times, harsh conditions [6a] and it is sensitive to the scale up. Interestingly, the monocoupling between compound $\mathbf{1}$ and 2-bromothiophene $\left(\mathrm{K}_{2} \mathrm{CO}_{3}\right.$, pivOH, $\mathrm{Pd}(\mathrm{OAc})_{2}, \mathrm{PCy}_{3-}$ $\mathrm{HBF}_{4}$, tol., reflux), gives the dimer $\mathbf{5}$ in satisfying yield 

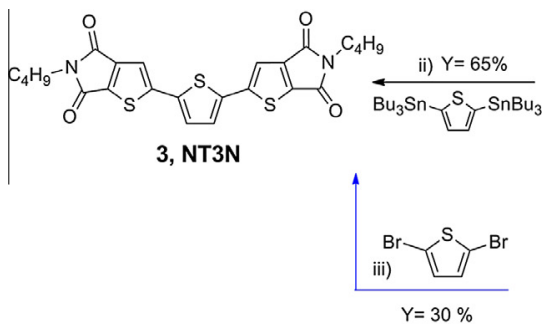

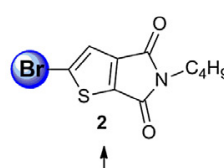
i) $Y=78 \%$

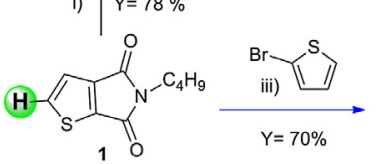

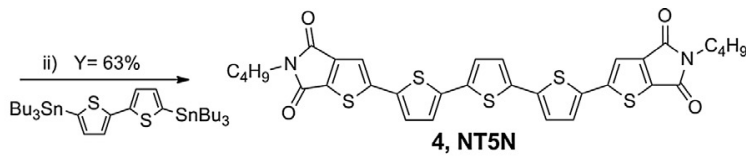

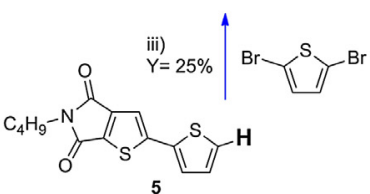

Scheme 1. Synthesis of NT3N and NT5N by Stille coupling (black path) and by direct arylation (blue path). (i) NBS, TFA, $\mathrm{H}_{2} \mathrm{SO}_{4}, 48 \mathrm{~h}$. (ii) Refluxing toluene, in situ $\mathrm{Pd}\left(\mathrm{AsPh}_{3}\right)_{4}, 8 \mathrm{~h}$. (iii) $\mathrm{K}_{2} \mathrm{CO}_{3}$, pivOH, $\mathrm{Pd}(\mathrm{OAc})_{2}, \mathrm{PCy}_{3} \mathrm{HBF}_{4}$, toluene, reflux $24 \mathrm{~h}$. (For interpretation of the references to color in this figure legend, the reader is referred to the web version of this article.).

(70\%), however, only moderate yields were achieved when double coupling reactions were attempted. In particular, NT3N and NT5N were obtained in 25-30\% yields, recording as major products the brominated monoadducts. The reason of the partial conversion is still not clear but we believe that the poorer solubility of the brominated intermediate plays a major role.

\subsection{Optoelectronic properties}

The optoelectronic properties of the newly synthesized materials were investigated by UV-Vis absorption and photoluminescence, as well as by theoretical calculations. UV-Vis absorption analysis shows a red shift of the maximum absorption wavelength on passing from NT3N to NT4N to NT5N ( $\lambda_{\max }=428 \mathrm{~nm}, 449 \mathrm{~nm}$ and $465 \mathrm{~nm}$ respectively, Fig. $1 \mathrm{a}$ and data in Table 1 ).

Luminescence followed the same trend showing spectra with the $\lambda_{\max }$ located at $526 \mathrm{~nm}, 572 \mathrm{~nm}$ and $599 \mathrm{~nm}$ for NT3N, NT4N and NT5N respectively (Fig. 2, values in Table 1). In general a strong red shift for both the absorption and the emission spectra was observed for TBI based compounds with respect to unsubstituted analogues, this can be ascribed to the presence of the carboxylic groups of the diimide, which extends the degree of $\pi$-conjugation. Accordingly, lower band gap energies were calculated for TBI based compounds with respect to conventional T3, T4 and T5 having the same number of thiophene units respectively.

On going to thin films spectra (Fig. $2 \mathrm{~b}$ and $\mathrm{c}$ ), the absorption spectra extend to higher energies and are structured with respect to the solution spectra, as expected for an ordered system of interacting linear molecules. Indeed, the solid state PL spectra are less broad and more structured with respect to those in solution, with at least three peaks.

Moreover, only NT3N spectrum is clearly red-shifted with the respect to the correspondent one in solution. This feature suggests an extended delocalization of the electronic excitation-possibly due to a higher crystalline degree in solid-state for NT3N.

The cyclic voltammetries (CVs, Fig. 3a, data in Table 1) of NT3N show an irreversible oxidation wave with the half wave potential $E_{1 / 2}=1.49 \mathrm{~V}$ vs. SCE $\left(1.09 \mathrm{~V} \mathrm{vs}\right.$. Fc/Fc $\left.{ }^{+}\right)$, and a quasi-reversible reduction wave with the standard potential $E^{\circ}=-1.18 \mathrm{~V}$ vs. SCE $\left(-1.58 \mathrm{~V}\right.$ vs. $\left.\mathrm{Fc} / \mathrm{Fc}^{+}\right)$. Both for
Table 1

List of experimental and calculated optoelectronic parameters.

\begin{tabular}{|c|c|c|c|c|c|c|}
\hline Item & $\begin{array}{l}\lambda_{\mathrm{abs}} \\
\mathrm{sol} / \\
\text { film } \\
(\mathrm{nm})\end{array}$ & $\begin{array}{l}\lambda_{\mathrm{em}} \\
\text { sol/ } \\
\text { film } \\
(\mathrm{nm})\end{array}$ & $\begin{array}{l}E g_{\text {opt }} \\
(\mathrm{eV})^{\mathrm{a}}\end{array}$ & $\begin{array}{l}E g_{\text {electr }} \\
(\mathrm{eV})\end{array}$ & $\begin{array}{l}\text { HOMO } \\
(\mathrm{eV}) \\
\text { exp/ } \\
\text { theo }\end{array}$ & $\begin{array}{l}\text { LUMO } \\
(\mathrm{eV}) \\
\text { exp/ } \\
\text { theo }\end{array}$ \\
\hline NT3N & $\begin{array}{l}428 / \\
405\end{array}$ & $\begin{array}{l}526 / \\
550\end{array}$ & 2.89 & 2.67 & $\begin{array}{l}-6.17^{\mathrm{b}} / \\
-5.73\end{array}$ & $\begin{array}{l}-3.50^{\mathrm{b}} / \\
-2.80\end{array}$ \\
\hline NT4N ${ }^{c}$ & $\begin{array}{l}449 / \\
430^{c}\end{array}$ & $\begin{array}{l}572 / \\
603^{\mathrm{c}}\end{array}$ & 2.76 & 2.53 & $\begin{array}{l}-6.00^{\mathrm{b}} / \\
-5.51\end{array}$ & $\begin{array}{l}-3.47^{\mathrm{b}} \\
-2.62\end{array}$ \\
\hline NT5N & $\begin{array}{l}465 / \\
398\end{array}$ & $\begin{array}{l}599 / \\
620\end{array}$ & 2.66 & 2.35 & $\begin{array}{l}-5.82^{d} \\
-5.23\end{array}$ & $\begin{array}{l}-3.47^{\mathrm{d}} / \\
-2.74\end{array}$ \\
\hline T3 & $355^{\mathrm{e}}$ & $\begin{array}{l}407 / \\
426^{\mathrm{e}}\end{array}$ & 3.49 & 3.02 & $-5.58^{d}$ & $-2.56^{\mathrm{d}}$ \\
\hline $\mathrm{T} 4$ & $390^{\mathrm{e}}$ & $\begin{array}{l}437 / \\
478^{b}\end{array}$ & 3.17 & 2.71 & $-5.43^{d}$ & $-2.72^{\mathrm{d}}$ \\
\hline T5 & $416^{\mathrm{e}}$ & $\begin{array}{l}482 / \\
514^{\mathrm{e}}\end{array}$ & 2.98 & 2.52 & $-5.34^{d}$ & $-2.82^{\mathrm{d}}$ \\
\hline
\end{tabular}

a $E g_{\text {opt }}=1240 / \lambda_{\max }$.

${ }^{\mathrm{b}} E_{\mathrm{HOMO}}=e\left(4.68+\mathrm{E}^{\circ} \mathrm{OX}\right) ; E_{\mathrm{LUMO}}=e\left(4.68+E^{\circ}\right.$ red $)$ vs. $\mathrm{SCE}[16]$.

c From Refs. [6b,c].

d $E_{\mathrm{HOMO}}=e\left(4.62+E^{\circ} \mathrm{Ox}\right) ; E_{\mathrm{LUMO}}=e\left(4.62+E^{\circ}\right.$ red $) \mathrm{vs} . \mathrm{Ag} / \mathrm{AgCl}[21]$.

e In $\mathrm{CHCl}_{3}$ values taken from The Handbook of Oligo-and Polythiophenes [22]. Film thickness $100 \mathrm{~nm}$.

NT3N and NT5N, the plot of the reduction and oxidation current maxima vs. the square rote of the scan rate (inset of Fig. 3) fit the line, indicating a simple diffusion limited kinetics of the redox processes. The energies of frontier orbitals can be estimated as $E_{\mathrm{HOMO}}=-6.17 \mathrm{eV}$ and $E_{\mathrm{LUMO}}=-3.50 \mathrm{eV}$, consequently the electrochemical band gap was $E g_{\text {elec }}=2.67 \mathrm{eV}$ (Table 1) [20].

NT5N shows a quasi-reversible oxidation wave at $1.14 \mathrm{~V}$ vs. SCE $\left(0.67 \mathrm{~V}\right.$ vs. $\left.\mathrm{Fc} / \mathrm{Fc}^{+}\right)$and a quasi reversible reduction one at $-1.21 \mathrm{~V}$ vs. SCE $\left(-1.68 \mathrm{~V}\right.$ vs. Fc/Fc ${ }^{+}$, Fig. 2b). As expected the electrochemical band gap was $E g_{\text {elec }}=2.35 \mathrm{eV}$, i.e., lower than that of the shorter analogues.

DFT calculations show that the HOMO orbital in all cases is delocalized over the entire molecular backbone. Interestingly, the LUMO orbital is mainly localized at the oligomer ends on the electron withdrawing TBI, $\mathrm{N}$ moieties (Fig. 4). Accordingly, while the HOMO levels increase from NT3N to NT5N, the LUMO energy value is almost unaffected by the conjugation length (Table 1 ) as also observed for TBI based tetramers [6c]. 


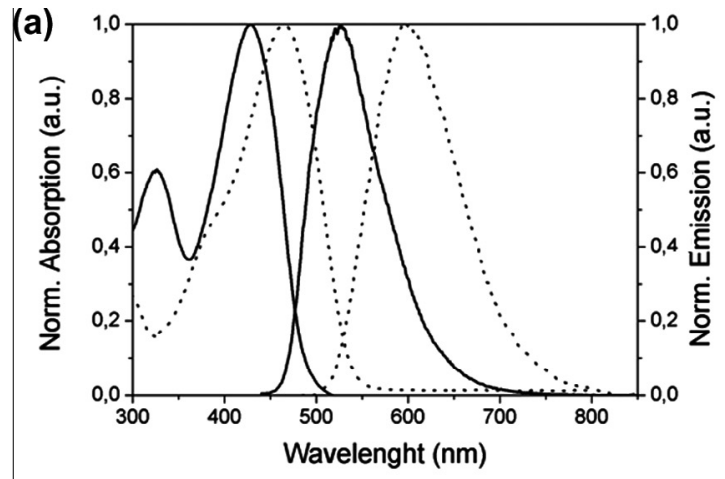

(b)

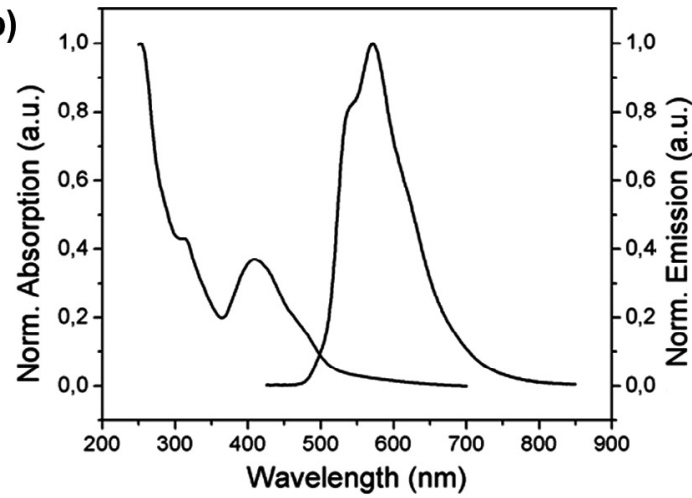

(c)

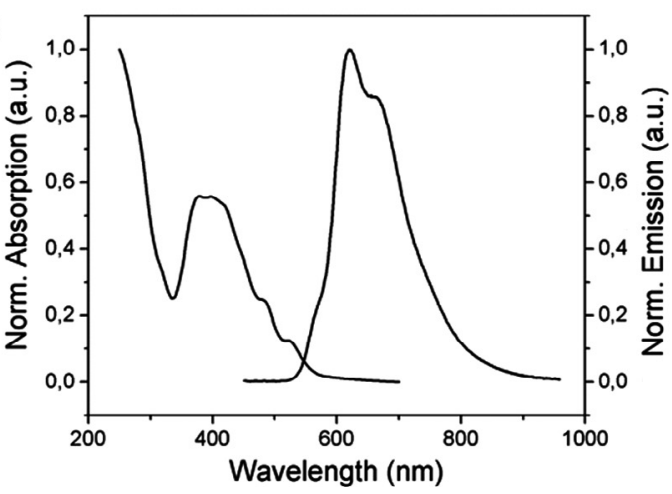

Fig. 2. (a) UV-Vis spectra of NT3N (solid line) and NT5N (dotted lines) and corresponding PL spectra (dotted lines), in $\mathrm{CH}_{2} \mathrm{Cl}_{2}$. (b) UV-Vis and PL spectra of NT3N and (c) of NT5N thin films (100 nm thick).

As for the TBI analogues the HOMO energy of conventional T3, T4 and T5 increases on increasing the conjugation length but for these compounds contrarily to the TBIs the LUMO energy decrease on going from T3 to T5.

\subsection{Thin film morphologies and electrical properties}

In order to determine the field-effect transport properties of the new compounds, a bottom gate-top contact OFET based on vacuum evaporated films (30 nm thick) were realized and characterized. Fig. $5 a$ and b shows the AFM topographical image of the vacuum evaporated films
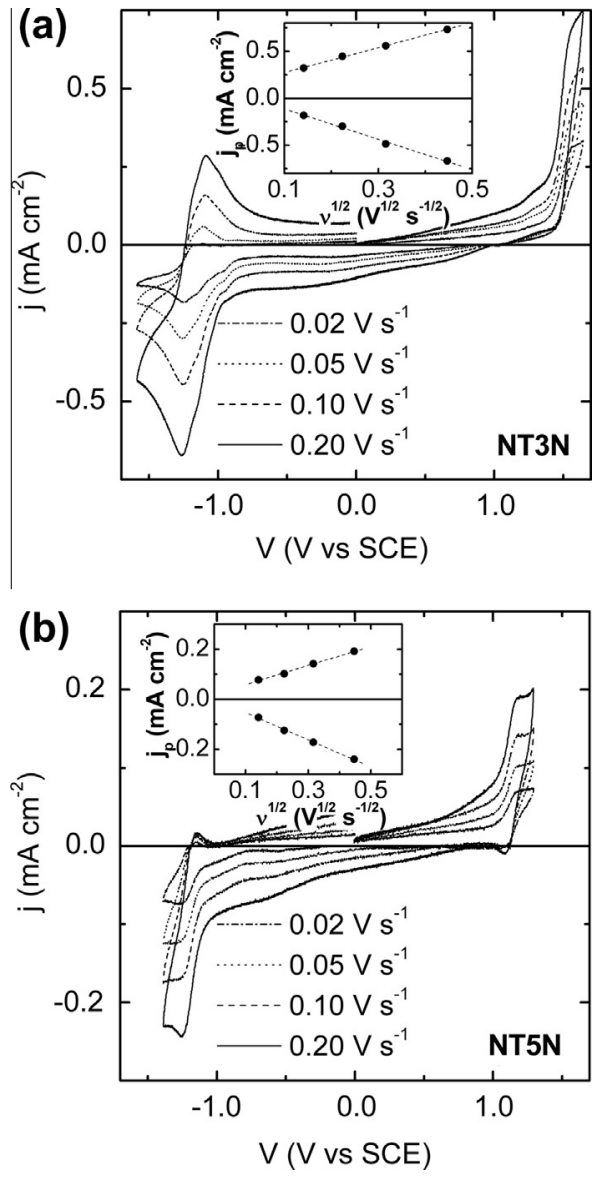

Fig. 3. CVs at several scan rate of (a) NT3N and (b) of NT5N. In the inset the peak currents vs. the square rote of the scan rate.
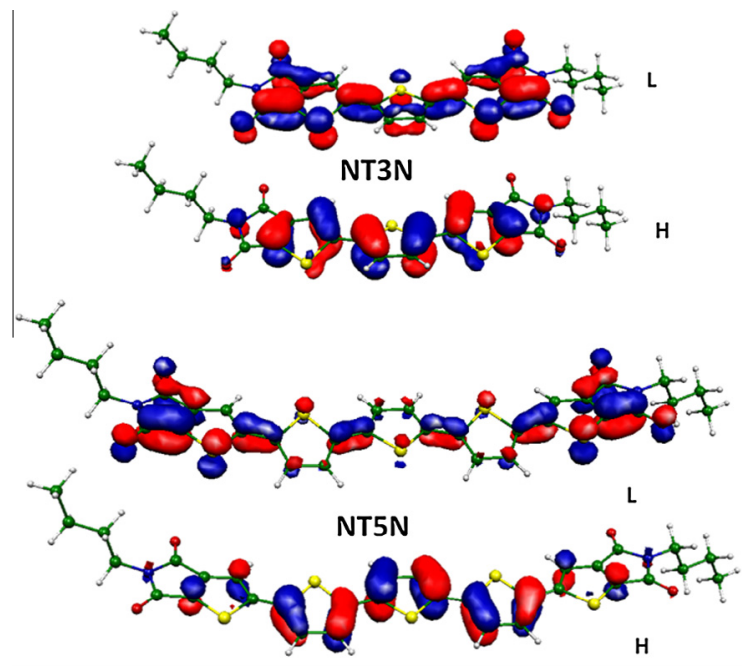

Fig. 4. Isodensity for the LUMOs and HOMOs levels of NT3N (top) and NT5N (down).

of NT3N and NT5N. The film of NT3N appears homogeneous at large scale with a r.m.s. roughness of about $4 \mathrm{~nm}$, and is formed by a homogeneous distribution of 

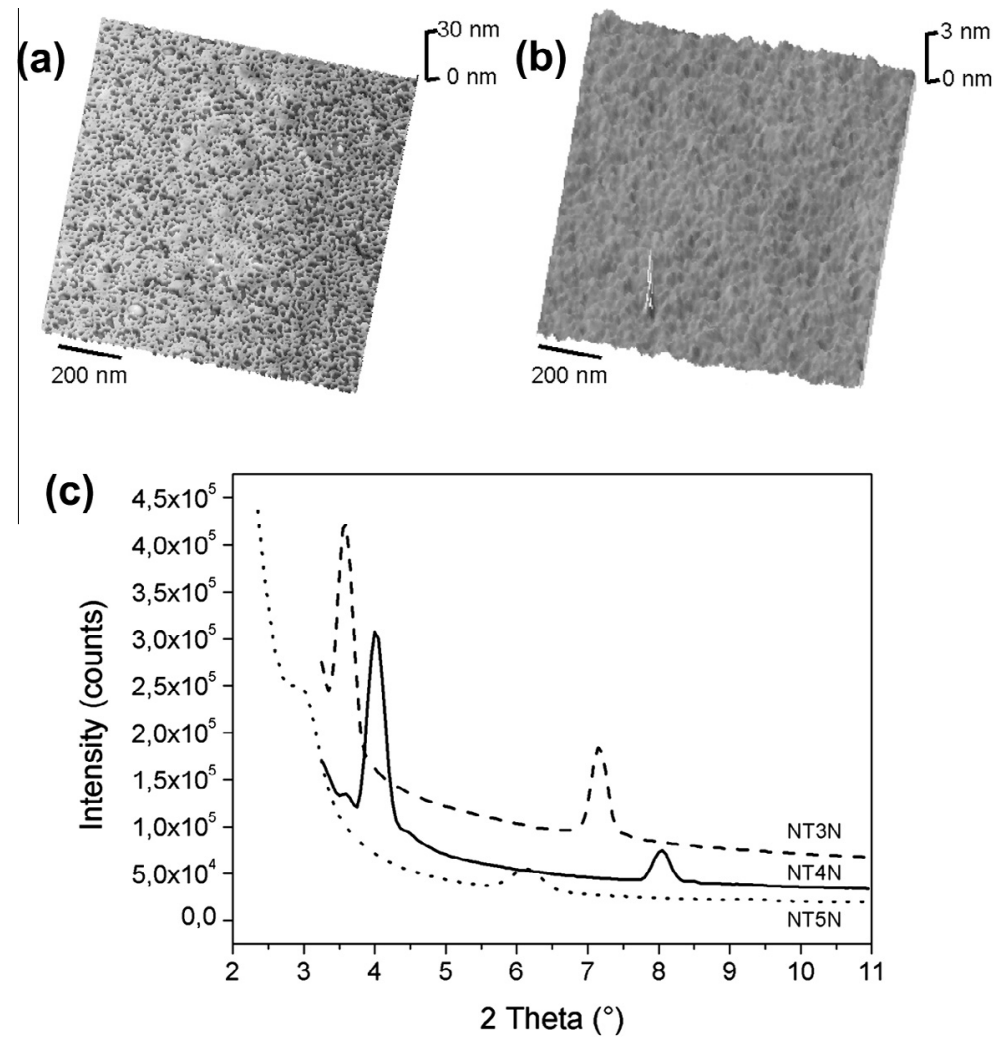

Fig. 5. AFM images of vacuum evaporated thin films (a) of NT3N, $15 \mathrm{~nm}$ thick, (b) of NT5N, $30 \mathrm{~nm}$ thick, and (c) XRD on the same films.

fibers structures covering $\sim 60 \%$ of the surface area (Fig. 5a). On the other hand NT5N, similarly to NT4N [6c], forms a highly homogeneous and smooth film with a r.m.s. roughness of about $6 \AA$ A. Although occasionally some out of plane growth was observed, no sign of phase segregation nor recrystallization were observed in evaporated films.

Fig. 5c, shows the X-ray Diffraction profiles of the vacuum sublimed films. The lower angle peaks are located at $2.2 \mathrm{~nm}, 2.4 \mathrm{~nm}$, and $2.8 \mathrm{~nm}$ for NT3N, NT4N and NT5N respectively and almost correspond to their molecular length (2.4, 2.8 and $3.2 \mathrm{~nm}$ respectively). This suggesting a vertical, tilted orientation of the molecules with respect to the substrate.

Fig. 6 shows the output locus and saturation curves of the newly synthesized materials. OFETs based on NT3N show exclusively electron transport with mobility $\mu_{e}=10^{-4} \mathrm{~cm}^{2}$ $\mathrm{V}^{-1} \mathrm{~s}^{-1}$. To the best of our knowledge this is the only case of linear terthiophene reported so far showing charge transport, in particular n-type one. Indeed, n-type behavior with mobility values up to $0.2 \mathrm{~cm}^{2} \mathrm{~V} \mathrm{~s}^{-1}$ in air [9b] has been reported only for quinoidal dicyanomethylene end functionalized terthiophenes, $[9 b, d]$ while no charge transport was found for non-quinoidal perfluorohexyl end substituted terthiophene [23] pertaining to one of the most investigated class of n-type small molecule semiconductors [8].

Moreover, differently from conventional T5 [10a] and perfuoro-end-substituted T5 [18] that are unipolar, NT5N based devices were ambipolar confirming that the TBI insertion in oligothiophenes promotes ambipolar charge carrier transport [6]. Data in Table 2, also show that an increase of the electron charge mobility values $\left(10^{-4}\right.$ $\rightarrow 10^{-2} \rightarrow 10^{-1} \mathrm{~cm}^{2} \mathrm{~V}^{-1} \mathrm{~s}^{-1}$ ) can be achieved on passing from NT3N to NT5N. The hole mobility values are instead insensitive to the oligomer size increasing. Indeed, the hole mobility, which is negligible for NT3N, remained unchanged for NT4N and NT5N. The unbalanced holes and electrons charge mobilities can derives by a complex interplay between optoelectronic and molecular packing properties. Indeed, contrarily to conventional oligothiophenes (also to perfluoroended ones) having the HOMO and LUMO orbital homogeneously distributed over the entire backbone, in TBI ended oligomers the LUMO is mainly located on the TBI moiety, i.e., at the oligomer periphery. We believe that in thin films, the adopted molecular packing allows a good LUMO's overlap (allowing the electron transport) but a poorer HOMO's overlap, this limiting the p-type contribute to charge transport. Deep theoretical studies in solid state are currently under way to confirm our hypothesis and will be subject of a forthcoming dedicated study. The molecular packing could also explain the increase in n-type mobility on increasing the oligomer length. Although, the single crystal structures of NT3N and NT5N are not known (no singles crystals could be isolated), XRD analysis of thin films, suggests that they adopt a $\pi$ stacking similar to that of NT4N for which structural analysis revealed a vertical molecular orientation, with respect to the substrate [6a], with a partial interdigitation between 

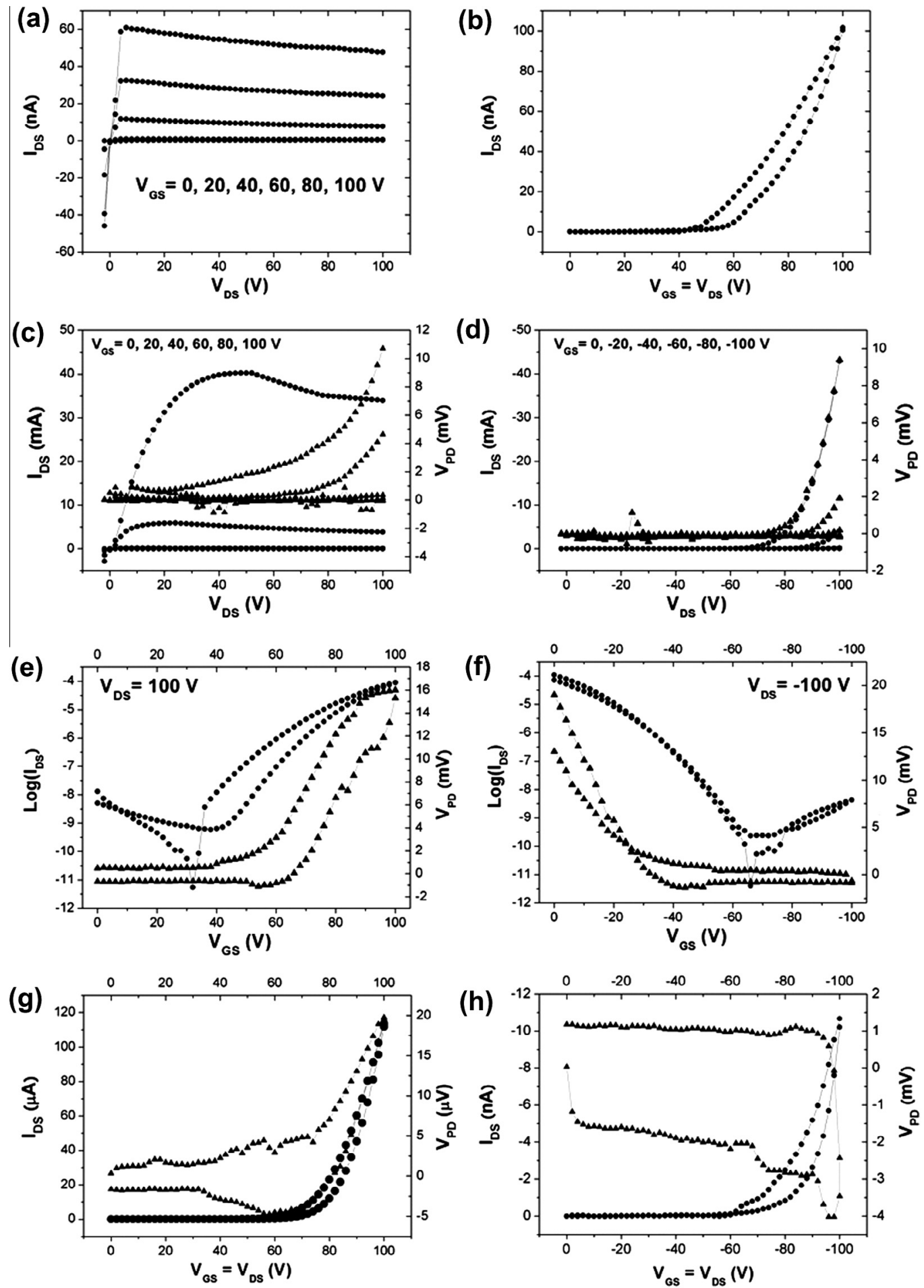

Fig. 6. Electrical characteristics of single layer OFET based on NT3N and NT5N. (a) n-type multiple output and (b) locus curves of NT3N. (c) n-type and (d) ptype multiple output curves for NT5N. (e) n-type and (f) p-type transfer saturation curves for NT5N. (g) n-type and (h) p-type locus curves for NT5N. Electroluminescence in arbitrary units from NT5N based devices is reported in the curves marked with triangles. Characterization was done in controlled $1 \mathrm{ppm} \mathrm{O}_{2}$ and $\mathrm{H}_{2} \mathrm{O}$ inside a nitrogen glove box.

overlapped layers. Therefore, assuming that the same $\pi$ stacking mode is adopted also by NT3N and NT5N, the increasing length and consequently the increasing $\pi$-elec- tron density, would improve the $\pi$-stacking attitude, promoting the enhanced charge transport capability on increasing the oligomer length. 
Table 2

List of charge mobilities, threshold voltages and $I_{\text {on/off }}$ values.

\begin{tabular}{llllll}
\hline Item & $\begin{array}{l}\mu_{\mathrm{h}} \\
\left(\mathrm{cm}^{2} \mathrm{~V}^{-1} \mathrm{~s}^{-1}\right)\end{array}$ & $\begin{array}{l}\mu_{\mathrm{e}} \\
\left(\mathrm{cm}^{2} \mathrm{~V}^{-1} \mathrm{~s}^{-1}\right)\end{array}$ & $\begin{array}{l}V_{\mathrm{Th}} \\
(\mathrm{V})\end{array}$ & $\begin{array}{l}V_{\mathrm{Te}} \\
(\mathrm{V})\end{array}$ & $\begin{array}{l}I_{\mathrm{on} /} \\
\text { off }\end{array}$ \\
\hline NT3N & - & $1.0 \times 10^{-4}$ & - & 31.7 & $10^{4}$ \\
NT4N $^{\mathrm{a}}$ & $6.4 \times 10^{-5}$ & $5.3 \times 10^{-2}$ & -71.0 & 60.0 & $10^{6}$ \\
NT5N & $1.6 \times 10^{-5}$ & $1.4 \times 10^{-1}$ & -60.3 & 64.3 & $10^{6}$ \\
\hline
\end{tabular}

${ }^{a}$ Data from Ref. [6a] (achieved by using the standard device preparation conditions used also for this work). For this compound higher mobility values were reported in Ref. [6c] in which the devices were prepared in different and optimized experimental conditions.

Fig. $6 \mathrm{c}-\mathrm{f}$ also show the electroluminescence signal, observed for NT5N during the OFETs characterization. NT4N and its non-symmetrical analogues have been already exploited for the realization of single layer ambipolar OLET devices [6c]. Interestingly, the EL displayed by NT5N, confirm the suitability of TBI based compounds different from quaterthiophenes, as ambipolar and electroluminescent materials for OLETs.

\section{Conclusions}

In summary, we have described the effects of the variation of the $\pi$-conjugation extent on the optoelectronic and electrical properties of TBI functionalized oligothiophenes. Two new TBI materials, having one less and one more thienyl ring than the previously reported TBI materials, namely NT3N and NT5N were synthesized for the first time by a direct arylation synthetic sequence starting from the halogen free TBI unit. Even if the yields were lower than those achieved by conventional Stille cross-coupling, this procedure appears very convenient since it allows to bypass the time and harsh condition demanding TBI bromination and to avoid the use of organometallic species. Optical analysis shows a strong red shift of both absorption and emission spectra with respect to conventional oligothiophenes having the same size. CVs and DFT calculations show that, while the HOMO energy level is strongly influenced by the number of conjugated units as observed for conventional oligothiophenes, the LUMO level, being localized on the TBI moiety, is poorly affected by the oligomer size. This is crucial for tuning the HOMO level while maintaining unchanged the LUMO. Despite the short oligomer size, significant electron mobility values (up to $10^{-4} \mathrm{~cm}^{2}$ $\mathrm{V}^{-1} \mathrm{~s}^{-1}$ ) were observed for NT3N. Notably, to the best of our knowledge up to now electron charge transport from substituted terthiophene was observed only for quinoidal-substituted terthiophene based oligomers bearing dicyanomethylene end groups [9b,d,e,f].

Our data also demonstrate that only by increasing the oligomer size to tetramer and pentamer, ambipolar semiconducting properties and electroluminescence can be achieved. Indeed, as previously observed for TBI based tetramers [6], also NT5N is ambipolar and electroluminescent, but it displays electron mobility value one order of magnitude higher than that of NT4N measured under the same experimental conditions [6a]. These results add relevant information for the engineering of new ambipolar materials currently lacking in the molecular semiconductors scenario. Investigation on further modification of the
TBI ends and on the influence on the functional properties of the resulting materials is currently under way.

\section{Acknowledgments}

The authors gratefully acknowledge the support of this work by the Consorzio MIST-ER through project FESR-tecnopolo AMBIMAT, by the project FP7-ICT-247928, Laser induced synthesis of polymeric nano composite materials and development of micro-patterned hybrid light emitting diodes and transistors (LAMP) and by the Italian MSE through project Industria 2015 (ALADIN).

\section{References}

[1] (a) C. Wang, H. Dong, W. Hu, Y. Liu, D. Zhu, Chem. Rev. 112 (2012) 2208;

(b) C. Di, F. Zhang, D. Zhu, Adv. Mater. 25 (2013) 313.

[2] (a) J. Zaumseil, H. Sirringhaus, Chem. Rev. 107 (2007) 1296;

(b) H. Yan, Z.H. Chen, Y. Zheng, C. Newman, J.R. Quinn, F. Dotz, M. Kastler, M.A. Facchetti, Nature 457 (2009) 679;

(c) H. Klauk, U. Zschieschang, J. Pflaum, M. Halik, Nature 445 (2007) 745;

(d) F.S. Kim, X.G. Guo, M.D. Watson, S.A. Jenekhe, Adv. Mater. 22 (2010) 478;

(e) H. Sirringhaus, T. Kawase, R.H. Friend, T. Shimoda, M Inbasekaran, W. Wu, E.P. Woo, Science 290 (2000) 2123;

(f) B. Yoo, B.A. Jones, D. Basu, D. Fine, T. Jung, S. Mohapatra, A. Facchetti, K. Dimmler, M.R. Wasielewski, T.J. Marks, A. Dodabalapur, Adv. Mater. 19 (2007) 4028;

(g) X. Guo, R.P. Ortiz, Y. Zheng, Y. Hu, Y.-Y. Noh, K.-J. Baeg, A. Facchetti, T.J. Marks, J. Am. Chem. Soc. 133 (2011) 1405.

[3] (a) M. Muccini, Nat. Mater. 5 (2006) 605;

(b) R. Capelli, S. Toffanin, G. Generali, H. Usta, A. Facchetti, M. Muccini, Nat. Mater. 9 (2010) 496;

(c) M. Muccini, W. Koopman, S. Toffanin, Laser Photon. Rev. 6 (2012) 258 .

[4] (a) K.C. See, C. Landis, A. Sarjeant, H.-E. Katz, Chem. Mater. 20 (2008) 3609;

(b) R.J. Chesterfield, J.C. McKeen, C.R. Newman, P.C. Ewbank, D.A. da Silva, J.L. Bredas, L.L. Miller, K.R. Mann, C.D. Frisbie, J. Phys. Chem. B 108 (2004) 19281;

(c) R.J. Chesterfield, J.C. McKeen, C.R. Newman, C.D. Frisbie, P.C. Ewbank, K.R. Mann, L.L. Miller, Appl. Phys. 95 (2004) 6396;

(d) P.R.L. Malenfant, C.D. Dimitrakopoulos, J.D. Gelorme, L.L. Kosbar, T.O. Graham, A. Curioni, W. Andreoni, Appl. Phys. Lett. 80 (2002) 2517;

(e) S. Tatemichi, M. Ichikawa, T. Koyama, Y. Taniguchi, Appl. Phys Lett. 89 (2006) 112108-112111;

(f) D. Shukla, S.F. Nelson, D.C. Freeman, M. Rajeswaran, W.G. Ahearn, D.M. Meyer, J.T. Carey, Chem. Mater. 20 (2008) 7486;

(g) X.W. Zhan, A. Facchetti, S. Barlow, T.J. Marks, M.A. Ratner, M.R Wasielewski, S.R. Marder, Adv. Mater. 23 (2011) 268.

[5] (a) H. Usta, C. Newman, Z. Chen, A. Facchetti, Adv. Mater. 24 (2012) 3678;

(b) R.P. Ortiz, H. Herrera, C. Seoane, J.L. Segura, A. Facchetti, T.J Marks, Chem. Eur. J. 18 (2011) 532;

(c) S.Z. Bisri, T. Takenobu, K. Sawabe, S. Tsuda, Y. Yomogida, T Yamao, S. Hotta, C. Adachi, Y. Iwasa, Adv. Mater. 23 (2011) 2753;

(d) C.A. Liu, Z.H. Liu, H.T. Lemke, H.N. Tsao, R.C.G. Naber, Y. Li, K. Banger, K. Mullen, M.M. Nielsen, H. Sirringhaus, Chem. Mater. 22 (2010) 2120;

(e) H. Usta, C. Risko, C.Z. Wang, H. Huang, M.K. Deliomeroglu, A. Zhukhovitiskiy, A. Facchetti, T.J. Marks, J. Am. Chem. Soc. 131 (2009) 5586;

(f) H.N. Tsao, W. Pisula, Z.H. Liu, W. Osikowicz, W.R. Salaneck, K. Mullen, Adv. Mater. 20 (2008) 2715;

(g) M.-H. Yoon, S.A. Di Benedetto, A. Facchetti, T.J. Marks, J. Am. Chem. Soc. 127 (2005) 1348.

[6] (a) M. Melucci, M. Zambianchi, L. Favaretto, M. Gazzano, A. Zanelli, M. Monari, R. Capelli, S. Troisi, S. Toffanin, M. Muccini, Chem. Commun. 47 (2011) 11840;

(b) M. Durso, D. Gentili, C. Bettini, A. Zanelli, M. Cavallini, F. De Angelis, M.G. Lobello, V. Biondo, M. Muccini, R. Capelli, M. Melucci, Chem. Commun. 49 (2013) 4298; 
(c) M. Melucci, L. Favaretto, M. Zambianchi, M. Durso, M. Gazzano, A. Zanelli, M. Monari, M.G. Lobello, F. De Angelis, V. Biondo, G. Generali, S. Troisi, W. Koopman, S. Toffanin, R. Capelli, M. Muccini, Chem. Mater. 5 (2013) 668.

[7] (a) M.C. Gwinner, D. Kabra, M. Roberts, T.J.K. Brenner, B.H. Wallikewitz, C.R. McNeill, R.H. Friend, H. Sirringhaus, Adv. Mater. 24 (2012) 2728;

(b) J. Zaumseil, C.R. McNeill, M. Bird, D.L. Smith, P.P. Ruden, M. Roberts, M.J. McKiernan, R.H. Friend, H. Sirringhaus, J. Appl. Phys. 103 (2008) 064517.

[8] (a) A. Mishra, C.-Q. Ma, P. Baüerle, Chem. Rev. 109 (2009) 1141;

(b) G. Barbarella, M. Melucci, G. Sotgiu, Adv. Mater. 17 (2005) 1581.

[9] (a) J. Casado, R.P. Ortiz, J.T. Lopez Navarrete, Chem. Soc. Rev. 41 (2012) 5672;

(b) S. Handa, E. Miyazaki, K. Takimiya, Y. Kunugi, J. Am. Chem. Soc. 129 (2007) 11684;

(c) J.-C. Ribierre, S. Watanabe, M. Matsumoto, T. Muto, A. Nakao, T. Aoyama, Adv. Mater. 22 (2010) 4044;

(d) S. Handa, E. Miyazakia, K. Takimiya, Chem. Commun. (2009) 3919-39213919;

(e) T.M. Pappenfus, R.J. Chesterfield, C.D. Frisbie, K.R. Mann, J. Casado, J.D. Raff, L.L. Miller, J. Am. Chem. Soc. 124 (2002) 4184;

(f) R.J. Chesterfield, C.R. Newman, T.M. Pappenfus, P.C. Ewbank, M.H Haukaas, K.R. Mann, L.L. Miller, C.D. Frisbie, Adv. Mater. 15 (2003) $1278-1282$.

[10] (a) A. Yassar, C. Videlot, A. Jaafari, Sol. Energy Mater. Sol. Cells 90 (2006) 916;

(b) I. Viola, F. Della Sala, M. Piacenza, L. Favaretto, M. Gazzano, M. Anni, G. Barbarella, R. Cingolani, G. Gigli, Adv. Mater. 19 (2007) 1597.

[11] (a) M. Melucci, M. Gazzano, G. Barbarella, M. Cavallini, F. Biscarini, P. Maccagnani, P. Ostoja, J. Am. Chem. Soc. 125 (2003) 10266;

(b) M. Melucci, L. Favaretto, C. Bettini, M. Gazzano, N. Camaioni, P.
Maccagnani, P. Ostoja, M. Monari, G. Barbarella, Chem. Eur. J. 13 (2007) 10046.

[12] (a) M. Melucci, M. Zambianchi, F. Di Maria, M. Gazzano, M. Monari, M. Cavallini, Thin Solid Films 518 (2010) 4131;

(b) G. Generali, F. Dinelli, R. Capelli, S. Toffanin, F. Di Maria, M. Gazzano, G. Barbarella, M. Muccini, J. Phys. Chem. C 115 (2011) 23164.

[13] P. Ostoja, P. Maccagnani, M. Gazzano, M. Cavallini, J.C. Kengne, R. Kshirsagara, F. Biscarini, M. Melucci, M. Zambianchi, G. Barbarella, Synth. Met. 146 (2004) 243.

[14] (a) D.J. Schipper, K. Fagnou, Chem. Mater. 23 (2011) 1594;

(b) B. Liegault, D. Lapointe, L. Caron, A. Vlassova, K. Fagnou, J. Org. Chem. 74 (2009) 1826;

(c) M. Lafrance, K. Fagnou, J. Am. Chem. Soc. 128 (2006) 16496.

[15] A. Facchetti, L. Vaccaro, A. Marrocchi, Angew. Chem. Int. Ed. 51 (2012) 3520 .

[16] A.D. Becke, J. Chem. Phys. 98 (1993) 5648.

[17] R. Ditchfield, W.J. Hehre, J.A. Pople, J. Chem. Phys. 54 (1971) 724.

[18] see <http://www.gaussian.com/g_tech/g_ur/m_citation.htm>.

[19] (a) S. Miertš, E.S. Tomasi, J. Chem. Phys. 55 (1981) 117;

(b) M. Cossi, V. Barone, J. Chem. Phys. 115 (2001) 4708.

[20] (a) S. Trasatti, Pure Appl. Chem. 58 (1986) 955;

(b) G. Gritzner, J. Kuta, Pure Appl. Chem. 56 (1984) 461;

(c) M. Melucci, L. Favaretto, A. Zanelli, M. Cavallini, A. Bongini, P. Maccagnani, P. Ostoja, G. Derue, R. Lazzaroni, G. Barbarella, Adv. Funct. Mater. 20 (2010) 445.

[21] K. Meerholz, J. Heinze, Electrochim. Acta 41 (1996) 1839.

[22] D. Fichou (Ed.), The Handbook of Oligo-and Polythiophenes, WileyVCH Verlag GmbH, Weinheim, Germany, 1999.

[23] (a) A. Facchetti, M. Mushrush, H.E. Katz, T.J. Marks, Adv. Mater. 15 (2003) 33;

(b) R.J. Chesterfield, C.R. Newman, T.M. Pappenfus, P.C. Ewbank, M.H. Haukaas, K.R. Mann, L.L. Miller, C.D. Frisbie, Adv. Mater. 15 (2003) 1278. 